\title{
Potential Landslide Detection in Kelok Sembilan Flyover Using SAR Interferometry
}

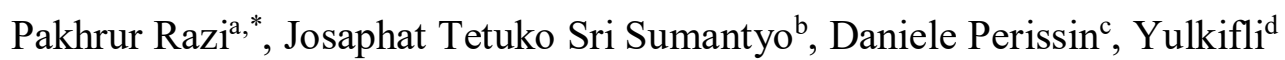 \\ ${ }^{a}$ Centre of Disaster Monitoring and Earth Observation, Physics Department, Universitas Negeri Padang, Padang, 25131, Indonesia \\ ${ }^{b}$ Centre of Environmental Remote Sensing, Chiba University, Chiba 236-8522, Japan \\ ${ }^{c}$ Lyle School of Civil Engineering, Purdue University, 550 Stadium Mall Drive, West Lafayette, IN, 47907 United States \\ ${ }^{d}$ Physics Department, Universitas Negeri Padang, Padang, 25131, Indonesia \\ Corresponding author: fhrrazi@fmipa.unp.ac.id
}

\begin{abstract}
Kelok Sembilan flyover is located in West Sumatra-Riau province connection, Indonesia. Landslide occurs along with the connection every year. However, detecting and obtaining scientific information about the potential landslide zone in the area is difficult because it is mountainous, and there is no disaster equipment monitoring installed on it. Here, we identify the area that potential landslide using Satellite Radar SAR Synthetic Aperture Radar) technology with high accuracy until millimeter unit. Also, we showed how to observe the potential landslide with a low penetrate radar signal (C-band) and shifted polarization due to the topography in the vegetation area. The observation data is extracting from satellite Sentinel- 1A/B provided by the European Space Agency (ESA). The satellite is C-band frequency with $5.5 \mathrm{~cm}$ wavelength and $5 \times 20$-meter range-azimuth resolution. The acquisition time of SAR data is starting from October 2014 to August 2018, which is supported by 119 images. Processing the SAR data is using the Quasi-Persistent Scatterer technique to improve the number of scatterers in a non-urban area. Both ascending and descending orbit of the satellite with both VV and VH polarization were selected to confirm potential landslide detection consistency. The result of processing was validated with GPS geodetic by DGPS network configuration. Based on the QPS processing, five areas with significant land movement have been detected; one of them is collapse after ten days since the last data observation. The land movement range in the area is approximately more than 500 millimeters in four years.
\end{abstract}

Keywords - Synthetic aperture radar; landslide; radar interferometry; sentinel-1.

Manuscript received 22 Nov. 2020; revised 12 Dec. 2020; accepted 18 Feb. 2021. Date of publication 30 Apr. 2021. IJASEIT is licensed under a Creative Commons Attribution-Share Alike 4.0 International License.

\section{INTRODUCTION}

Kelok Sembilan flyover is located in the main connection in the centre of Sumatra, Indonesia. The area is positioned at $0^{\circ} 4^{\prime} 13.70^{\prime \prime} \mathrm{S}$ and $100^{\circ} 41^{\prime} 54.75^{\prime \prime} \mathrm{E} 50$ Kota district, West Sumatra. The flyover is part of the way that spread of 153.2 $\mathrm{km}$ long which the landslide occurred every year [1]. In recent four years, the landslide recorded along the connection is on March 2017, with 64 locations [2], continue on October 3, 2018, December 12, 2018, November 24, 2019, December 4, 10, 20, 31, 2019, January 20, 22, 2020, February 3, 2020, September 21, 2020, October 29, 2020 [3].

The Kelok Sembilan flyover was built around a V-shaped area with a high slope based on the topographic on the area. The area is also close to the Solok-Bio-bio strike fault line that existed about $1 \mathrm{~km}$ on the western side. Furthermore, based on the geology structures, the area is complex and consists of tension joint, anticline, and syncline on both sides. This condition leads to improve vulnerability landslides in the area. Monitoring continuously in Kelok Sembilan flyover is required to determine which area has a high potential landslide, then can be scientific information in maintenance the construction which has spent much cost to build. No equipment is installed along the area to monitor the potential landslide in the Kelok Sembilan flyover.

In this research, identifying the potential landslide area, Radar SAR (Synthetic aperture radar) satellite technology provided by European Space Agency (ESA) is a sophisticated solution to detect and overcome the unavailability of landslide monitoring equipment on site. Besides, the radar data is free to access also has large data availability with a short temporal and normal baseline of 6 days and 200 meters, respectively [4], [5]. However, the limited penetration of the radar SAR signal due to the radar data is a C-band frequency that is applied in the non-urban (canopy) area, which will affect to lower the number of persistent scatterer (PS) detection than 
L-band [6], [7]. Furthermore, due to the flyover located in the ' $\mathrm{V}$ ' shape area, the radar satellite of Sentinel-1 flight parallel with the ' $V$ ' slope, the polarization radar signal will shift that induced by terrain slope [8].

Under the condition mentioned above, the quasi-persistent scatterer (QPS) technique was selected and applied to detect the potential landslide area in the Kelok Sembilan flyover. The technique is advanced of the original Persistent Scatterer Interferometry (PSI) that extracts the information from the partial coherence target [9] and then increases the spatial distribution of PS point detection [8]. The technique also allows the estimate of the signal shifting due to the slope area [10]. Furthermore, the technique overcomes the limitation of the Interferometry SAR (InSAR/D-InSAR) [11] technique that is influenced by the temporal and geometrical decorrelation and water vapor content effect [1], and extremely PS cut off in PSI technique [8]. Over the year, the QPS technique spread in many remote sensing applications included but not limited to mining applications [12], land subsidence [13], Monitoring of Tunneling [14], land deformation [15].

In processing, the QPS technique was supported by 119 number scenes of Sentinel-1 SAR data. The observation was starting from October 2014 to August 2018. The scenes were processed in ascending and descending orbits with $\mathrm{VV}$ (vertical transmit and vertical receive) and $\mathrm{VH}$ (vertical transmit and horizontal receive) polarization. The Geodetic GPS measurement (Geographical Positioned System) was installed in the area to measure the position (latitude, longitude, and high) of PS points during the observation to compare the result of QPS processing. The geodetic GPS equipment was configured with DGPS (Differential Geographical Positioned System) technique in one GCP (ground control point) (P6) and five rover points (P1-P5) (Fig. 7) to determine the GPC point carried out by selecting the stable point (no movement) of the QPS processing result.

The research aims to implement the QPS technique to observe the potential landslide area using C-band SAR applied in a non-urban area and V shape contour shape. The QPS technique compares with the Geodetic GPS equipment that is configured using the DGPS technique. Besides, in this research, we present, 1). The PS distribution in positive and negative slope due to terrain slope affects both ascending and descending orbits with VV and VH polarization. 2). The trend of land movement in potential landslide area detection. 3). Modeling the potential landslide area in the Kelok Sembilan flyover.

\section{MATERIAL AND MethoD}

\section{A. Material}

The sequences of satellite Sentinel-1 SAR data with an acquisition time from October 2014 to Augustus 2018 were used to observe the potential landslide zone in the Kelok Sembilan flyover. The data is C-band frequency with a 5.44 $\mathrm{cm}$ wavelength provided by ESA (European Space Agency) [16]. Both orbits of the satellites were selected in observation to obtain the information with high precision and consistency in detecting the potential landslide in the area. Also, its polarization in co-polarization VV (vertical transmit and vertical receive) and cross-polarization $\mathrm{VH}$ (vertical transmit and horizontal receive) were extracted. The dataset SAR satellite of Sentinel-1 is listed in Table 1.

TABLE I

Sentinel-1 A/B SATEllite Dataset For Ascending AND Descending ORBIT

\begin{tabular}{|c|c|c|c|c|c|c|}
\hline No & Orbit & $\begin{array}{l}\text { The } \\
\text { number } \\
\text { of } \\
\text { Scenes } \\
\end{array}$ & $\begin{array}{l}\text { Beam } \\
\text { swath } \\
\text { mode }\end{array}$ & $\begin{array}{l}\text { Acquisition } \\
\text { time }\end{array}$ & Polarization & $\begin{array}{l}\text { Off- } \\
\text { nadir } \\
\text { angle }\end{array}$ \\
\hline 1 & Ascending & 51 & IW1 & $\begin{array}{l}10 / 2014- \\
01 / 2018\end{array}$ & $\mathrm{VV}+\mathrm{VH}$ & $\begin{array}{l}26.00^{0}- \\
32.48^{0}\end{array}$ \\
\hline 2 & Descending & 68 & IW3 & $\begin{array}{l}10 / 2014- \\
08 / 2018\end{array}$ & $\mathrm{VV}+\mathrm{VH}$ & $\begin{array}{l}35.35^{0}- \\
40.40^{0}\end{array}$ \\
\hline
\end{tabular}

Both orbits of Sentinel-1 A/B datasets were processed in a single look complex (SLC) format. The SLC data format consists of phase and amplitude information that has focused and georeferenced using altitude and orbit data from the satellite [17], [5]. Also, the data in zero Doppler slant-range geometry [18]. From three-part of beam swath mode of Interferometric Wide (IW) of Sentinel-1, IW1 and IW3 were selected for the study area in both ascending and descending orbits, respectively. IW1 in ascending and descending orbit has a low off-nadir angle than IW3 because its beam swath close to a perpendicular off-nadir angle, then the number of persistent scatterers (PS) detection large than IW3. The spatial resolution for both beam swath modes is $2.7 \times 22.5$ meters (IW1) and $3.5 \times 22.6$ meters (IW3) in ascending and descending orbit [19], respectively. Furthermore, the SAR satellite of Sentinel-1 A/B has a large critical baseline Bn, with an inclination angle of $98.18^{0}$ and a repeat cycle of 6 days [20], then more data can be co-registration.

\section{B. Methods}

In processing the SAR data Q-PS (Quasi Persistent Scatterer), the Interferometry technique was selected. The Quasi Persistent scatterer technique is advanced from the original PSI (Persistent Scatterer Interferometry) technique [10], [21] that can be developed to extracting the information from the partial coherence target. The primary purpose of the technique is to improve the number of persistent scatterers (PS) in spatial distribution, particularly in a non-urban area [22], [23], [24]. Also, the technique provided tools to estimate the phase-shifted. The main reason selected the technique was the area located in V shape, high vegetation, and topography.

The MST (Minimum spanning Tree) network configuration was selected to maximize the coherence radar target $\gamma$ minimize the atmospheric effect. Also, the connectivity of the images, the number of the link, and the weight of each link were considered. In identification PS, QPS technique extracts the coherence target with high temporal phase-coherent that defined as [11], [17], [25], [26], [27].

$$
\gamma_{T}=\frac{1}{N}\left|\sum_{i=1}^{N} e^{j\left(\Delta \varphi_{T}^{i, j}-\Delta \varphi_{H, T}^{i, j}-\Delta \varphi_{D, T}^{i, j}\right)}\right|
$$

Where the component $\Delta \varphi_{T}^{i, j}$ is interferometric phase acquiring that do not depend on the elevation and the liner deformation trend, $\Delta \varphi_{H, T}^{i, j}$ is interferometric phase depends on the elevation, $\Delta \varphi_{D, T}^{i, j}$ is the interferometric phase of 
deformation trend for point target $\mathrm{T}$, and $\mathrm{N}$ is the number of images. The phase component that depends on the height and linear deformation is presented, respectively, by [11], [28].

$$
\Delta \varphi_{H, O, T}^{i, j}=\frac{4 \pi}{\lambda} \frac{1}{R \sin \theta} \Delta h_{T, O} B n_{i, j}
$$

and

$$
\Delta \varphi_{D, O, T}^{i, j}=\frac{4 \pi}{\lambda} \Delta v_{T, O} B t_{i, j}
$$

Where $\lambda$ is wavelength radar signal, $\mathrm{R}$ is the slant range radar to target distance, $\theta$ is look-angle of radar satellite, $\Delta h_{T, O}$ is the elevation of point target T relative to control point $\mathrm{O}, B n_{i, j}$ is normal baseline images $\mathrm{i}$ and $\left.\mathrm{j}, \Delta v_{T, O}\right)$ is deformation trend point target $\mathrm{T}$ relative to control point $\mathrm{O}$ and $B t_{i, j}$ is the temporal baseline between images $\mathrm{i}$ and $\mathrm{j}$.

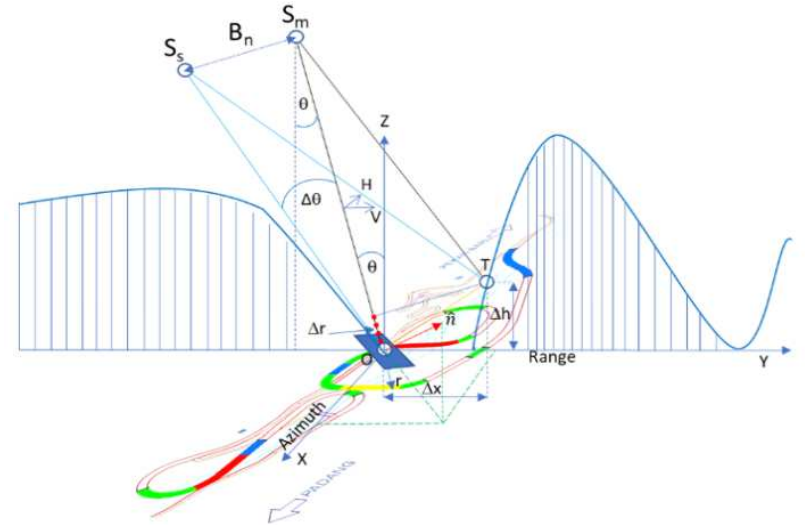

Fig. 1 The schematic radar geometry. It is related to the orientation angle to the ground slope in the Kelok Sembilan flyover area. The $\mathrm{x}$-axis represents the azimuth direction, and the $y$-axis represents the ground range direction. The surface normal to ground land is indicated by $\hat{n}$.

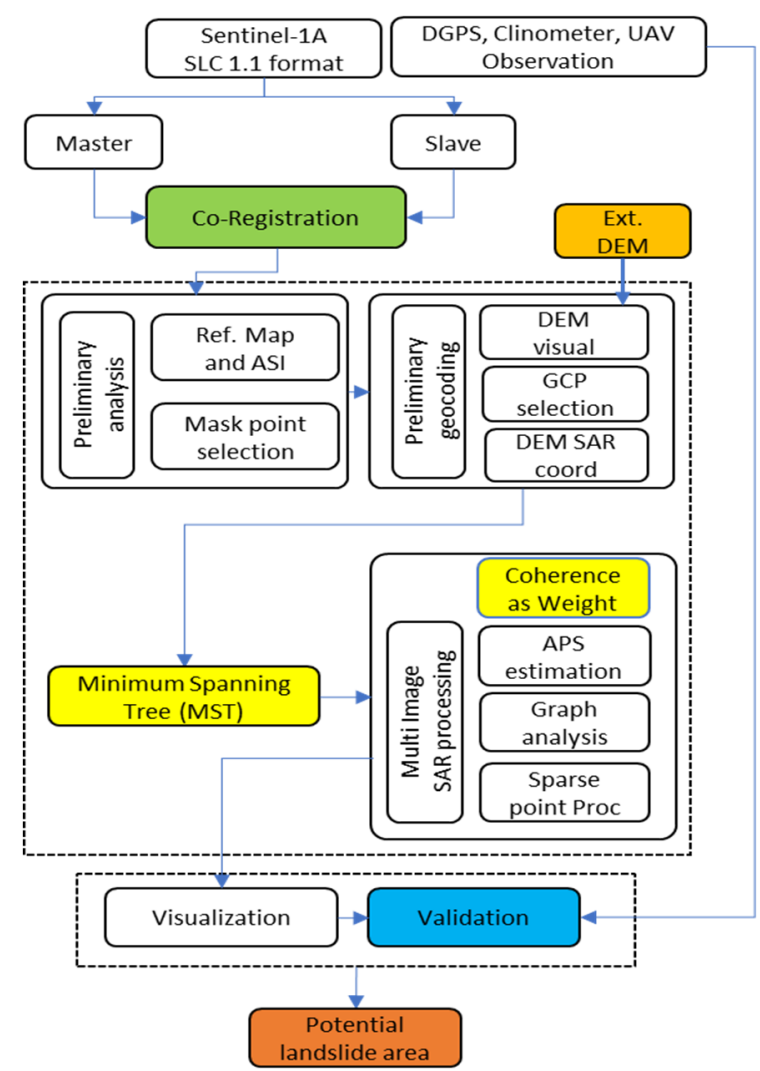

Fig. 2 The schematic of the QPS processing chain flow and validation process of the research

In-ground truth observation, the QPS technique was validated using geodetic GPS data measured in the study area. In GPS measurement, Differential GPS techniques were applied with one base station and five rover points. Also, its slope was measured with a clinometer instrument and UAV observation.

\section{RESULTS AND DISCUSSION}

\section{A. Persistent Scatterer (PS) Distribution and its Density for Both Ascending and Descending Orbit}

PS distribution and its density is an essential parameter to determine the accuracy of the land deformation. Besides the object's structure and material in every resolution cell, we found some factors that induced PS distribution and density: SAR frequency, resolution of SAR images, bandwidth, incidence angle $\theta \mathrm{i}$, and polarization.

Fig. 3 presents the distribution and density of PS points on the Kelok Sembilan flyover. The zones toward satellite perpendicular (near range) have high distribution and density of PS for both satellite directions and polarization. However, ascending orbit with VV polarization (Fig. 3A-1) has the highest PS point distribution and density than other satellite data experiments. This result is because the dataset of the satellite is single polarization (SV) $\mathrm{VV}$, with bandwidth twofold in range resolution than double polarization (DV) VV $+\mathrm{VH}$ (Fig. 3A-2, 3A-3 and 3A-3). High resolution in the SAR data range improves the number of PS in the range direction. 
Besides, the satellite observed in low local incidence angle $\theta_{\mathrm{i}}$ of 34.1 degrees. Meanwhile, the other experimental data have an angle of 44.1 degrees (Fig. 3A-2, 3A-3, and 3A-3). Then the observation with a low incidence angle contributes to improving the density and number of PS detection.

In equal bandwidth and incidence angle, the distribution of PS and its density observed by co-polarization VV is higher than cross-polarization VH but less sensitive to detect the land movement. Moreover, regarding the area with ' $\mathrm{V}$ ' contour shape, $\mathrm{VV}$, and $\mathrm{VH}$ polarization less distribution and density in positive slope for ascending and descending tracks (positive slope for ascending = negative slope in descending and vice versa). It is because the radar signal is affected by the terrain azimuth slope. When the range slope is toward the radar (positive), the orientation of angle measurements is overestimated and vice versa for the negative slope.
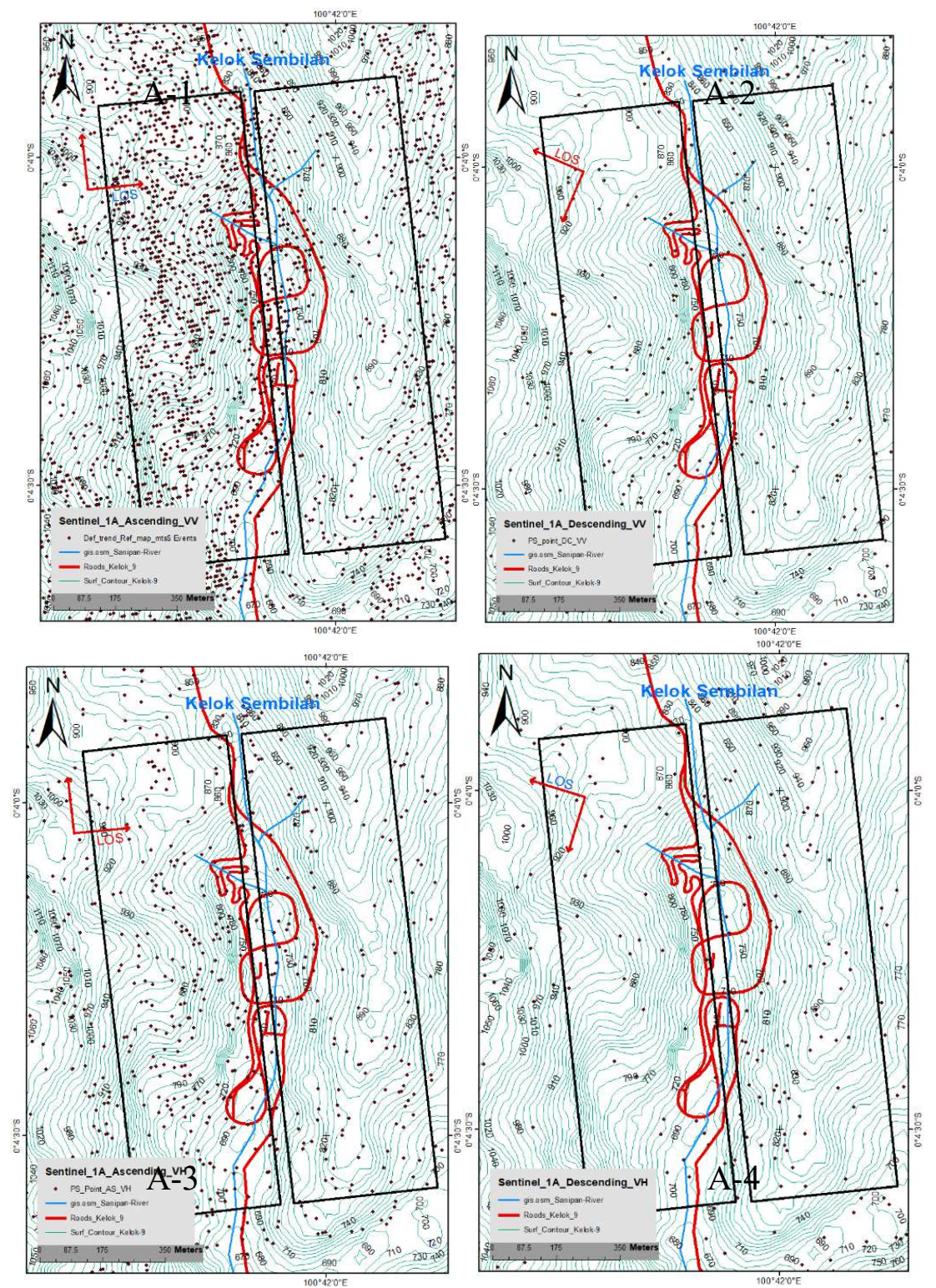

Fig. 3 PS distribution and its density for both ascending and descending orbits in VV and VH polarizations. A-1 ascending orbit with VV polarization, A-2 descending orbit with VV polarization, A-3 ascending orbit with VH polarization, A-4 descending orbit with VH polarization. The Redline is the main road, and Kelok Sembilan flyover and the blue line is the Sanipan River.

TABLE II

PS Distribution AND DENSITY For DifFERENT SATELLITE ORBITS AND POLARIZATIONS IN (2.78) KM2 AREA

\begin{tabular}{|c|c|c|c|c|c|c|c|c|}
\hline \multirow{3}{*}{ Slope } & \multicolumn{4}{|c|}{ Ascending } & \multicolumn{4}{|c|}{ Descending } \\
\hline & \multicolumn{2}{|c|}{$\mathrm{VV} \theta_{i}=34.1^{0}$} & \multicolumn{2}{|c|}{ VH $\theta_{i}=44.1^{0}$} & \multicolumn{2}{|c|}{$V V \theta_{i}=44.1^{0}$} & \multicolumn{2}{|c|}{$\mathrm{VH} \theta_{i}=44.1^{0}$} \\
\hline & Positive & Negative & Positive & Negative & Positive & Negative & Positive & Negative \\
\hline $\begin{array}{l}\text { Distribution } \\
\text { (N point) }\end{array}$ & H 324 & VH 673 & L 155 & Н 260 & L 122 & H 150 & VL 53 & H 112 \\
\hline $\begin{array}{l}\text { Density } \\
\text { (PS/km2) }\end{array}$ & 116 & 242 & 56 & 94 & 43 & 53 & 19 & 40 \\
\hline
\end{tabular}

(H=high, VH=very high, L=low, VL=very low) 
Table 2 compares the distribution and density PS point of SAR data with VV and VH polarization for ascending and descending orbits in the positive and negative slopes area. The data was classified based on the number and density of PS inside the square (black) line in both areas.

\section{B. Modeling the Potential Landslide}

Using the Inverse Distance Weight (IDW) interpolation technique, the potential landslide area was depicted based on the distribution and density of PS points on the study area. Fig. 5 presents the potential landslide area modeling based on the IDW interpolation technique in contour shape. Satellite data observation with ascending orbit and VV polarization is modeled in (Fig. 4B-1), and descending orbit with VV polarization is in (Fig 4B-2). With this data, five areas have significant land movement detected in both direction and VV polarization. Four areas are located on the slope and one in the flat with 500 millimeters of movement. The area out of the black square line in the positive and negative slope (Fig. 3) is not an object in this research.

The observation using ascending orbit with $\mathrm{VH}$ polarization depicted in Fig. 4B-3 and descending orbit with VH polarization show in Fig. 4B-4. Observation using ascending and descending orbit with $\mathrm{VH}$ polarization only detect the land movement in negative slope and failed for positive slope (negative slope for ascending $=$ positive slope for descending and positive slope for ascending = negative slope for descending) orbit. The observation using copolarization VV success identifies the potential landslide on both positive and negative slope that is observed from ascending and descending orbit. However, in crosspolarization $(\mathrm{VH})$ observing from both ascending and descending orbit is sensitive in negative slope (low-look angle) and loss for the positive slope.
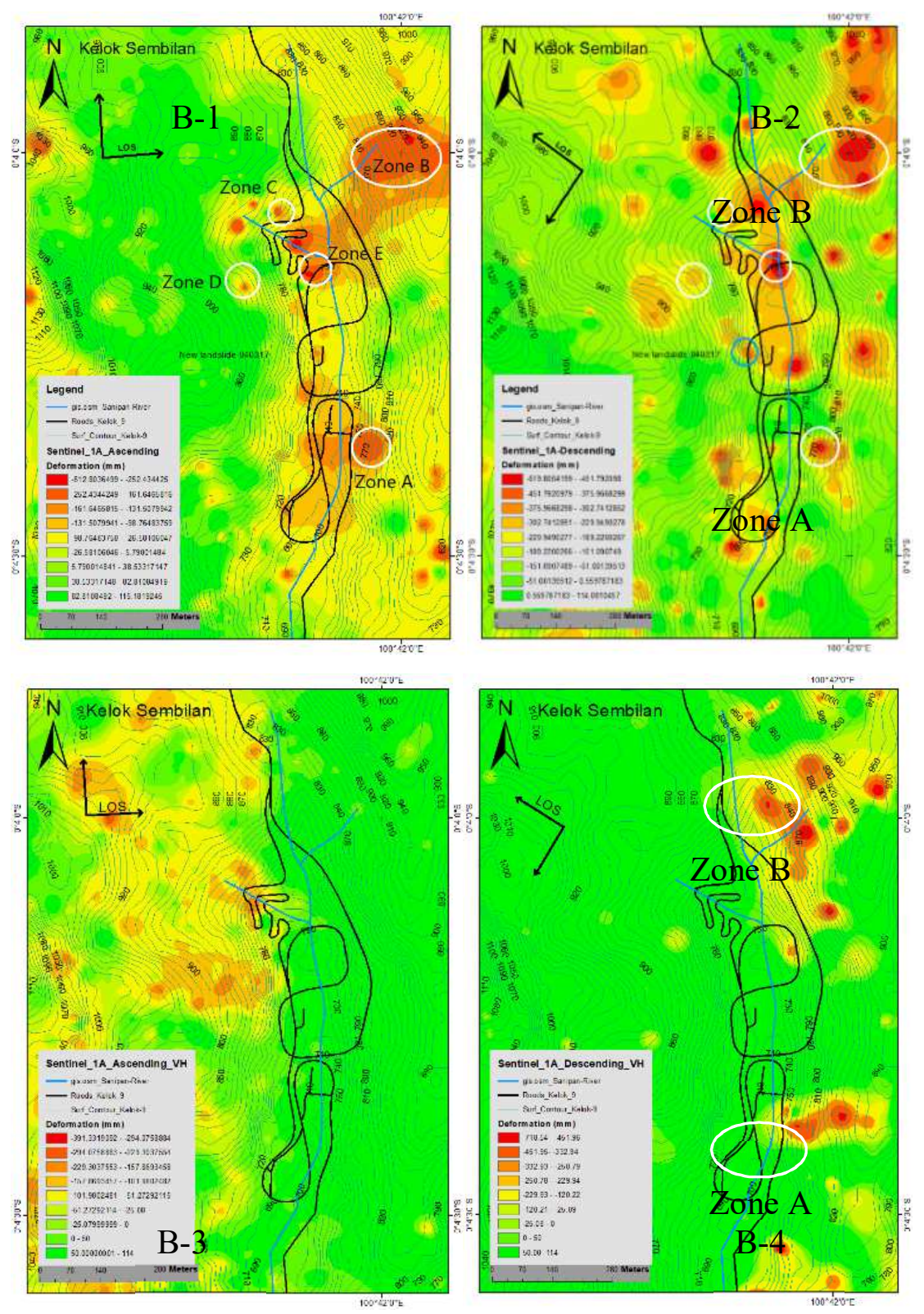

Fig. 4 The modelling of the potential landslide area in Kelok Sembilan flyover as observed by Sentinel $1 \mathrm{~A} / \mathrm{B}$ with VV and VH polarization in ascending and descending orbits. The black line is Kelok Sembilan road and flyover, the blue line is Sanipan River, and the arrow line is the range and azimuth direction of the Sentinel-1 A/B satellite observation. Insert left figure is a legend that shows the land deformation value in millimeters unit. 
Based on the model in (Fig. 4), there are two areas (zone A and zone B) of five zones with significant land movement detected consistently in both orbit direction and polarization. The area has movement with range $-217.6 \mathrm{~mm}$ to $-561.9 \mathrm{~mm}$ and located on a positive slope for ascending orbit or negative slope for descending orbit. The land deformation maximum on the area reaches 700 millimeters in four years (Fig.4B-4). Detailed profile of two areas with significant land deformation in zone A and zone B is presented in Fig. 5 and Fig. 6.

Fig. 5 and Fig. 6 show the profile of two of five zones that has significant land deformation observed from both satellite orbits and polarization. The PS point ID that represented the area depicted in the elevation and slope area was measured based on a Digital Elevation Model. For zone A (Fig. 5), the area observation is represented by ID 476 and ID 264 located approximately at $737.5 \mathrm{~m}$ and $737 \mathrm{~m}$ above sea level, with the local slope of 74.1 degrees and 73.8 degrees and the incidence angle $\theta_{\mathrm{i}}$ of 34.1 degrees and 44.1 degrees for ascending and descending orbits, respectively. The different position of elevation detection of the target is due to the different duration in acquisition time, where the descending orbit observation is nine months longer than that of the ascending. Consequently, the land movement value for descending orbit is also higher than that of the ascending, -561.9 millimeters and -217.6 millimeters for ascending orbit in the LOS. For zone B (Fig. 6 ), it has a similar land deformation pattern with zone A, represented by ID 950 and ID 126 for both ascending and descending orbits. The point target moves far away from the satellite with a maximum LOS of -253.3 millimeters and 535.3 millimeters and local slopes of 76.7 degrees and 73.5 degrees, respectively.
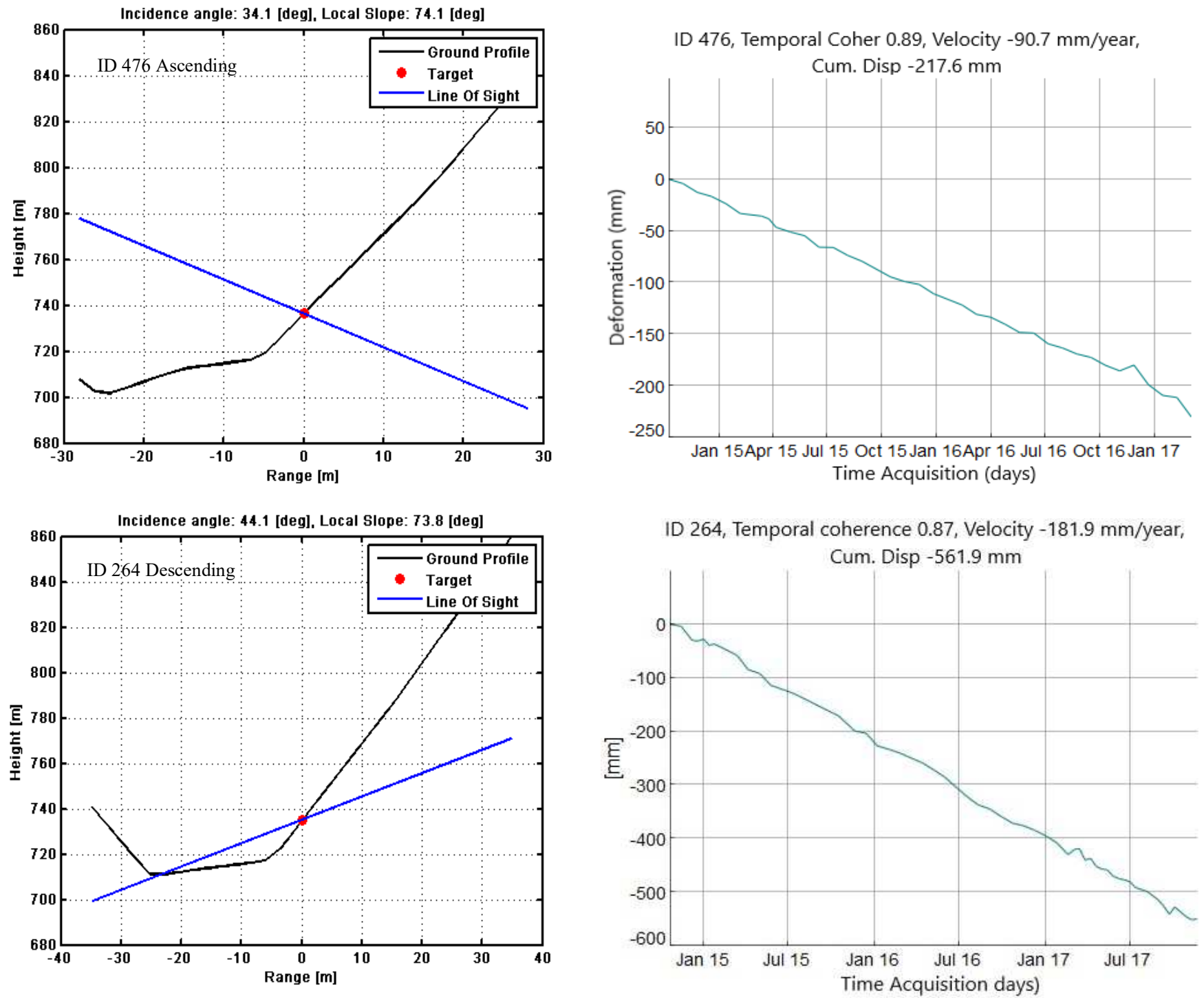

Fig. 5 Land deformation profile of Kelok Sembilan flyover for zone A was observed for ascending and descending orbits represented by PS ID 476 and ID 264 , respectively. Blueline is a Line of Sight (LOS) of the satellite. The black line is the zones' slope profile, and the red point is the PS position (target) on the DEM with incidence angle $\theta \mathrm{i}$ of 34.1 degrees and 44.1 degrees in both directions, respectively. The deformation trend of the target of the area is depicted on the right side of the slope profile. 


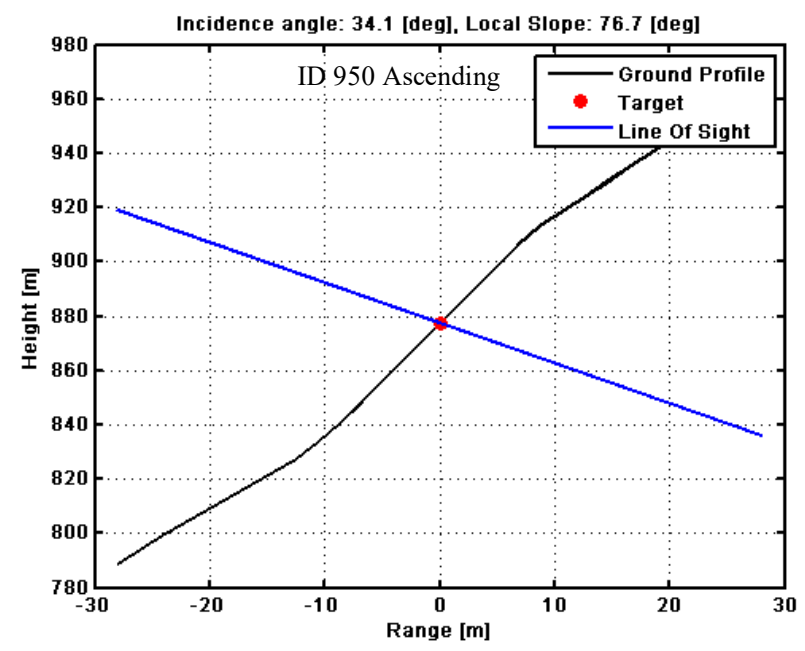

ID 950, Temporal Coher 0.79, Velocity $-105.6 \mathrm{~mm} / \mathrm{year}$,
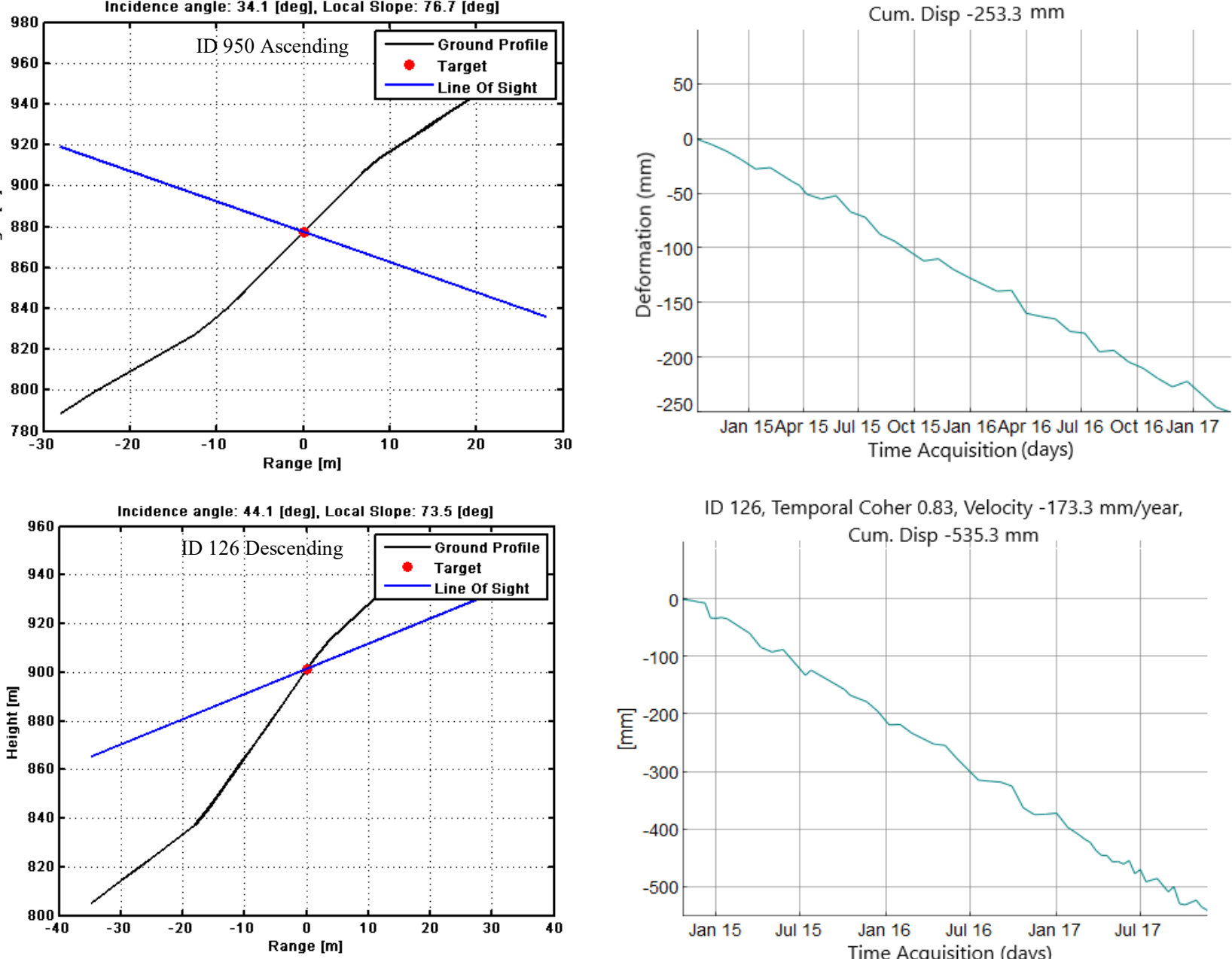

ID 126, Temporal Coher 0.83, Velocity $-173.3 \mathrm{~mm} /$ year,

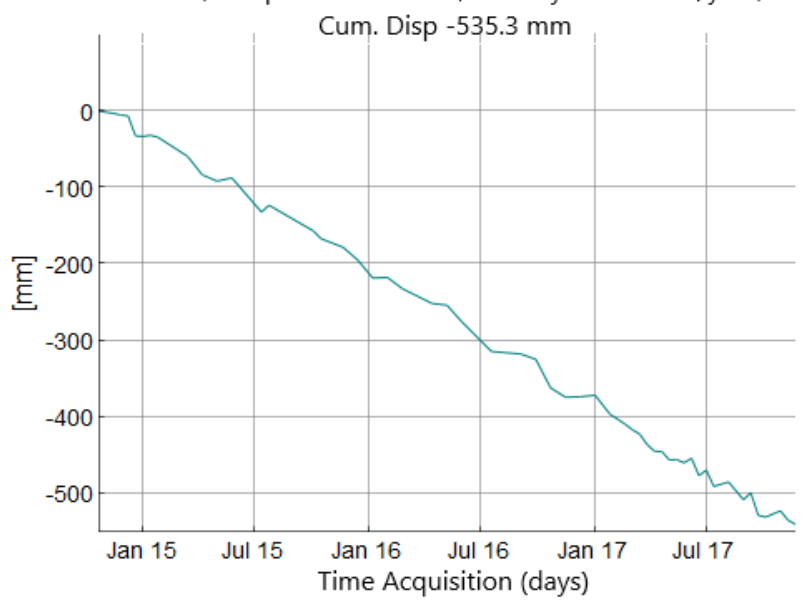

Fig. 6 Land deformation profile of Kelok Sembilan flyover for zone B in ascending and descending orbits observation is represented by PS ID 950 and ID 126, respectively. The blue line is a Line of Sight (LOS) of the satellite. The black line is the zones' slope profile, and the red point is the PS position (target) on the DEM with incidence angle $\theta \mathrm{i}$ of 34.1 degrees and 44.1 degrees in both directions, respectively. The deformation trend of the target of the area depicted on the right side of the slope profile.

The ground truth campaigns validate the QPS processing taken in two periods. The first term was from 16 September to 18 September 2016 , and the second term was from 3 September to 16 September 2018. The collecting data was using the geodetic GPS of LEICA instrument 1200 plus series, UAV phantom 3 professional series, Clinometer, and measuring tape. Using geodetic GPS, the collecting data by DGPS network configuration with post-processing technique in six-point measurements for both terms of the ground survey.

Point 1 (P1) has a significant change than the other points, approximately $170.2 \mathrm{~mm}$ and followed by point 2 (P2) 110.1 $\mathrm{mm}$ and point 3 (P3) $60.3 \mathrm{~mm}$. Points 4 (P4), point 5 (P5), and P6 (GCP) are relatively stable, with movements around 19.4, 14.3, and 13.3 millimeters, respectively. Therefore, zone A and zone B have a movement of approximately $90.6 \mathrm{~mm}$ and $217.6 \mathrm{~mm}$, respectively. According to the QPS measurement at the flyover in zone A and the road at zone B, the land movement is around $252.5 \mathrm{~mm}(\mathrm{P} 1)$ and $118.3 \mathrm{~mm}(\mathrm{P} 3)$. The QPS measurement is higher than Geodetic GPS because both techniques measure the different duration of time. Q-PS technique is observed in 46 months (from October 2014 to August 2018), while GPS in 24 months (from September 2016 to September 2018). The DGPS network configuration is shown in Fig. 7.

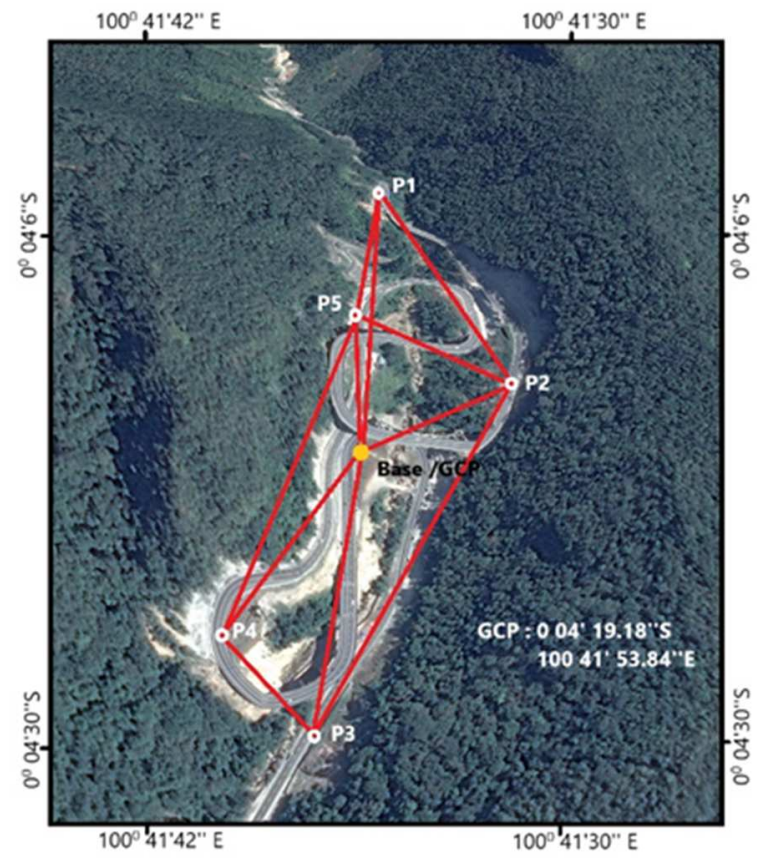

Fig. 7 The network configuration of DGPS technique measurement using Geodetic GPS Leica 1200 plus at Kelok Sembilan. P1-P5 is the rover position, and the yellow point marks ground control point P6 (GCP). 
Moreover, Clinometer was used to measure the slope of the flyover, especially for the flyover in zone B. For seven points measurement, the flyover has tilted by 6-9 degrees. The flyover's wall is no longer symmetrical on both sides, and each side moves around $2-4 \mathrm{~cm}$. This movement happened because in the south part of the bridge was subsidence (Fig. 8).

Fig. 8 depicts the potential landslide area obtained from ascending and descending SAR orbits which were modeled based on the IDW (Inverse Distance Weighted) interpolation technique. The technique was selected because it has successfully demonstrated the land movement until small, covered areas. There are five zones of potential landslide detection on the positive and negative slopes of the Kelok Sembilan flyover. Two of them are critical, namely, zone A and zone B that have a significant area covering potential landslides with more than 500-millimetre maximum land movement in four years.

One month since the last data observation, the landslide occurred on September 26, 2018, in zone B (opposite to the flyover). On the left part of the flyover, the blue cycle shows a landslide area in May 2016 and March 2017. In the middle of the valley, some land deformation was also detected, which was caused by the construction of the park. Based on the ground truth survey that was observed using UAV, there is a clear distinction of regions that have moved with their surroundings in zone A and zone B. The comparing result of measurement with the QPS technique and geodetic GPS is presented in Table 3.

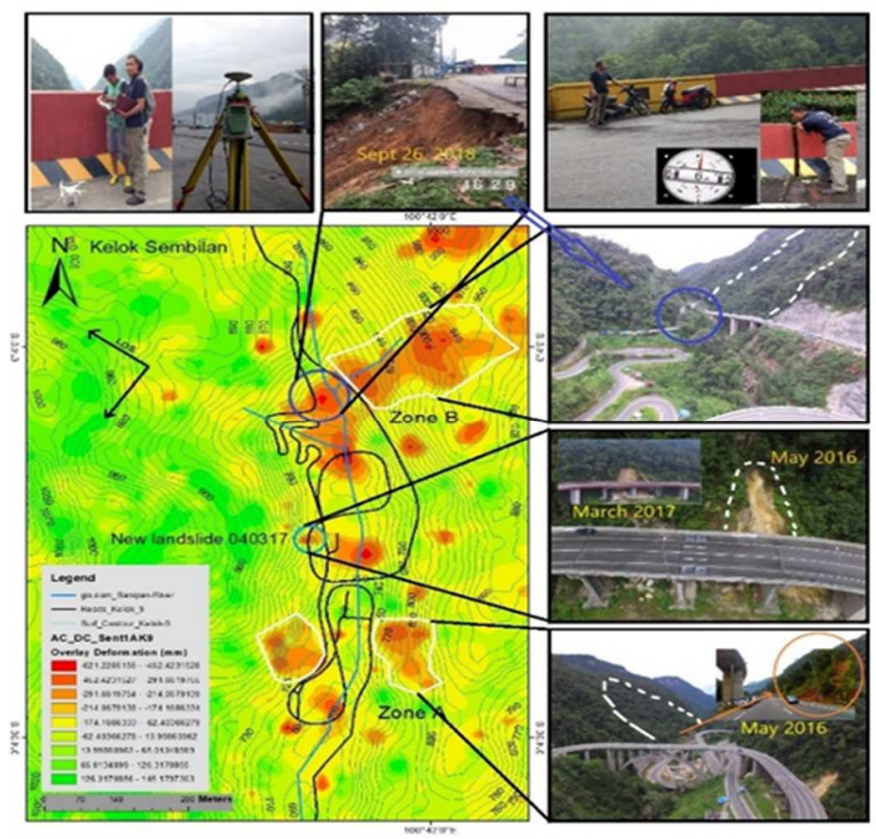

Fig. 8 Potential landslide detection and modelled obtained from both ascending and descending orbits of Sentinel-1A with VV and VH polarization. The data projected into a 12-meter resolution digital elevation model (DEM). In the five areas with significant movement, two of them have the highest value located in zone A and zone B. One area close to zone B collapsed on September 26, 2018. Insert picture on left-bottom shows the land deformation displacement in millimeter unit and scale of area in meters.

TABLE III

THE COMPARISON RESUlt OF Q-PS TECHNIQUE AND GPS GEODETIC OBSERVATION

\begin{tabular}{|c|c|c|c|c|c|c|c|c|c|}
\hline \multirow[b]{2}{*}{ PS ID } & \multicolumn{3}{|c|}{ Q-PS Technique } & \multicolumn{5}{|c|}{ GPS Geodetic } & \multirow{2}{*}{$\begin{array}{c}\text { Height Error } \\
\%\end{array}$} \\
\hline & LAT & LON & $\underset{(\mathbf{m m})}{\Delta \text { Height }}$ & LAT & LON & $\begin{array}{c}1^{\text {st }} \text { Survey } \\
\text { Height } \\
\text { (m) }\end{array}$ & $\begin{array}{l}2^{\text {nd }} \text { Survey } \\
\text { Height (m) }\end{array}$ & $\underset{(\mathbf{m m})}{\Delta \text { Height }}$ & \\
\hline $\mathrm{P} 1$ & -0.07428 & 100.6975 & 252.5 & -0.07427 & 100.6975 & 688.30 & 688.13 & 170.2 & 0.82 \\
\hline $\mathrm{P} 2$ & -0.07363 & 100.6980 & 83.1 & -0.07363 & 100.6979 & 687.62 & 687.51 & 110.1 & 0.27 \\
\hline P 3 & -0.07000 & 100.6980 & 118.3 & -0.07000 & 100.6978 & 727.71 & 727.65 & 60.3 & 0.58 \\
\hline P4 & -0.06832 & 100.6977 & 80.3 & -0.06823 & 100.6976 & 760.01 & 759.82 & 19.4 & 0.61 \\
\hline P5 & -0.07424 & 100.6987 & 62.4 & -0.07406 & 100.6986 & 662.72 & 662.57 & 14.3 & 0.48 \\
\hline P6 (GCP) & -0.07192 & 100.6985 & 17.7 & -0.07192 & 100.6984 & 687.51 & 687.37 & 13.3 & 0.04 \\
\hline & & & & & & & Average & eight Error & 0.38 \\
\hline
\end{tabular}

\section{CONCLUSION}

A combination of ascending and descending orbit and $\mathrm{VV}+\mathrm{VH}$ polarization with $\mathrm{C}$-band of sentinel-1A has successfully detected the potential landslide in Kelok
Sembilan flyover build in the middle ' $V$ ' contour shape of the mountain. Furthermore, for modelled the landslide, both orbit and polarization overlaid and interpolated using the IDW technique and then projected into a 12-meter resolution of digital elevation model (DEM). Two of the five zones have 
significant displacement with more than 500 millimeters and a $160 \mathrm{~mm} /$ year velocity from the analysis. One of five areas has collapsed after a ten-days after the last ground truth observation.

Other than that, this research shows the effect of shifting radar signal in $\mathrm{V}$ contour shape of the area to the number of persistent scatterers (PS) point distribution and density in both positive and negative slopes. The distribution of PS and its density observed by co-polarization VV is higher than crosspolarization $\mathrm{VH}$ but less sensitive to the land movement for ascending and descending orbits. Therefore, in dealing with the $\mathrm{V}$ shape effect, besides estimate and compensate using software, satellite datasets such as incidence angle, polarization, bandwidth, and orbit direction should be considered in data selection to obtain more PS points detection. The number of PS points correlated with the level of accuracy and precision of the potential landslide area detected.

Furthermore, the result of QPS processing was validated with ground truth data in situ measurement recorded using Geodetic GPS LEICA 1200 plus instruments, 3D Photogrammetry technique, Clinometer, and measuring tape. Finally, it can be summarized that 1) The combination of SAR data from both orbit and polarization can be used to monitor and model potential landslide in the $\mathrm{V}$ shape area with shortwavelength (C-band) that applied in a non-urban area, 2). The V slope affected PS points' distribution and density in VV and $\mathrm{VH}$ polarizations with different off-nadir angles and range resolution.

\section{ACKNOWLEDGEMENT}

We are grateful to the European Space Agency (ESA), JAXA, Japan, the USGS, RASER limited, Universitas Negeri Padang, and Chiba University.

\section{REFERENCES}

[1] P. Razi, J. T. S. Sumantyo, D. Perissin, H. Kuze, M. Y. Chua, and G F. Panggabean, "3D land mapping and land deformation monitoring using persistent scatterer interferometry (PSI) ALOS PALSAR: Validated by Geodetic GPS and UAV," IEEE Access, vol. 6, pp. 12395-12404, 2018.

[2] BNPB, "Data and Disaster Information of Indonesia," http://dibi.bnpb.go.id, 2019. [Online]. Available: http://dibi.bnpb.go.id/data-bencana/lihat-data.

[3] BNPB, "Indonesian disaster database," BNPB cloud, 2020. [Online]. Available: http://bnpb.cloud/dibi/xdibi_list. [Accessed: 03-Nov-2020].

[4] P. Razi, J. T. S. Sumantyo, F. Febriany, M. Nasucha, and J. Aminuddin, "Interferometry Synthetic Aperture Radar (InSAR) Application for Flood Area Detection Observed by Sentinel-1A," in Progress in Electromagnetics Research Symposium, 2018, pp. 905-909.

[5] M. Lazeckỳ et al., "Displacements monitoring over Czechia by IT4S1 system for automatised interferometric measurements using Sentinel1 data," Remote Sens., vol. 12, no. 18, pp. 1-21, 2020.

[6] S. E. L. Howell et al., "Comparing L- and C-band synthetic aperture radar estimates of sea ice motion over different ice regimes," Remote Sens. Environ., vol. 204, no. October 2017, pp. 380-391, 2018.

[7] M. El Hajj, N. Baghdadi, H. Bazzi, and M. Zribi, "Penetration analysis of SAR signals in the C and L bands for wheat, maise, and grasslands," Remote Sens., vol. 11, no. 1, pp. 22-24, 2019.

[8] S. Schaufler, B. Bauer-Marschallinger, S. Hochstöger, and W. Wagner, "Modelling and correcting azimuthal anisotropy in sentinel-1 backscatter data," Remote Sens. Lett., vol. 9, no. 8, pp. 799-808, 2018.

[9] D. Perissin, Z. Wang, C. Prati, and F. Rocca, "Terrain monitoring in China via PS-QPS InSAR: Tibet and the three gorges dam," Eur. Sp. Agency, (Special Publ. ESA SP, vol. 704 SP, pp. 2-6, 2013.

[10] D. Perissin and T. Wang, "Repeat-pass SAR interferometry with partially coherent targets," IEEE Trans. Geosci. Remote Sens., vol. 50, no. 1, pp. 271-280, 2012.

[11] D. Perissin, "Interferometric SAR Multitemporal Processing: Techniques and Applications," in Multitemporal Remote Sensing, Remote Sensing and Digital Image Processing, no. 20, Springer, Cham, 2016, pp. 145-176.

[12] M. S. Alam, D. Kumar, V. Sharma, and S. K. Chaudhary, "Land surface deformation parameter estimation using persistent scatterer interferometry approach in an underground metal mining environment," Imaging Sci. J., vol. 66, no. 5, pp. 289-302, 2018.

[13] M. Gao et al., "Land subsidence and ground fissures in Beijing Capital International Airport (BCIA): Evidence from Quasi-PS InSAR analysis," Remote Sens., vol. 11, no. 12, 2019.

[14] M. Roccheggiani, D. Piacentini, E. Tirincanti, D. Perissin, and M. Menichetti, "Detection and monitoring of tunneling induced ground movements using Sentinel-1 SAR interferometry," Remote Sens., vol. 11, no. 6, pp. 1-14, 2019.

[15] J. Fang et al., "The $2018 \mathrm{Mw} 7.5$ Palu earthquake: A supershear rupture event constrained by InSAR and broadband regional seismograms," Remote Sens., vol. 11, no. 11, pp. 1-15, 2019.

[16] ESA, "Interferometric wide swath," Esa 2000-2019, 2020. [Online]. Available: https://sentinel.esa.int/web/sentinel/user-guides/sentinel-1sar/acquisition-modes/interferometric-wide-swath. [Accessed: 11Aug-2020]

[17] ESA, "Level-1 SLC product," ESA Sentinel online, 2020. [Online]. Available: $\quad \mathrm{https} / /$ sentinel.esa.int/web/sentinel/technicalguides/sentinel-1-sar/products-algorithms/level-1-algorithms/singlelook-complex

[18] P. Razi, J. T. S. Sumantyo, K. Nishi, J. Widodo, A. Munir, and F. Febriany, "Effect of Earthquake Intensity to Land Deformation Observed from Space," Prog. Electromagn. Res. Symp., vol. 2019. June, pp. 2123-2128, 2019.

[19] ESA, "Resolution and Swath," Esa Sentinel online, 2020. [Online]. Available: https://sentinel.esa.int/web/sentinel/missions/sentinel1/instrument-payload/resolution-swath. [Accessed: 10-Apr-2020].

[20] P. Razi, J. Tetuko, S. Sumantyo, J. Widodo, Y. Izumi, and D. Perissin, "Land Deformation Monitoring Using D-InSAR Technique During Lombok Earthquake Observed By Sentinel-1 A / B," vol. 19, no. 73, pp. 257-262, 2020 .

[21] P. Razi, J. T. S. Sumantyo, D. Perissin, F. Febriany, and Y. Izumi, "Multi-Temporal Land deformation monitoring in V shape area using Quasi-Persistent Scatterer (Q-PS) Interferometry Technique," in 2018 Progress in Electromagnetics Research Symposium, 2018, pp. 910 915.

[22] M. Crosetto, O. Monserrat, M. Cuevas-González, N. Devanthéry, and B. Crippa, "Persistent Scatterer Interferometry: A review," ISPRS J. Photogramm. Remote Sens., vol. 115, pp. 78-89, 2016.

[23] M. Simons and P. A. Rosen, Interferometric Synthetic Aperture Radar Geodesy, vol. 3. Elsevier B.V., 2015.

[24] D. H. T. Minh, R. Hanssen, and F. Rocca, "Radar interferometry: 20 years of development in time series techniques and future perspectives," Remote Sens., vol. 12, no. 9, pp. 1-18, 2020.

[25] F. Zhao and J. J. Mallorqui, "A Temporal Phase Coherence Estimation Algorithm and Its Application on DInSAR Pixel Selection," IEEE Trans. Geosci. Remote Sens., vol. 57, no. 11, pp. 8350-8361, 2019.

[26] A. Pepe and A. Pepe, "A Review of Interferometric Synthetic Aperture RADAR ( InSAR ) Multi-Track Approaches for the Retrieval of Earth ' s Surface," no. December, pp. 1-39, 2017.

[27] J. Jung and S. H. Yun, "Evaluation of coherent and incoherent landslide detection methods based on synthetic aperture radar for rapid response: A case study for the 2018 Hokkaido landslides," Remote Sens., vol. 12, no. 2, pp. 1-26, 2020

[28] P. Mastro, C. Serio, G. Masiello, and A. Pepe, "The multiple aperture SAR interferometry (MAI) technique for the detection of large ground displacement dynamics: An overview," Remote Sens., vol. 12, no. 7, 2020 . 